\title{
Elective Cesarean Section or Not? Risk of Advance Maternal Age at First Birth
}

\author{
Ika Saptarini $^{1 *}$, Anissa Rizkianti ${ }^{2}$, Teti Tejayanti, ${ }^{3}$ \\ \{dr.ikasaptarini@gmail.com ${ }^{1}$, anissarizkianti@gmail.com ${ }^{2}$, teti.teja@yahoo.co.id ${ }^{3}$ \} \\ *corresponding author
}

National Institute of Health Research and Development, Ministry of Health ${ }^{1,2,3}$

\begin{abstract}
The existing literature suggests that the increase of cesarean section (csection) is predominantly due to advanced maternal age (AMA), particularly in nulliparous women. We examined the association between AMA and elective c-section in primiparous women with singleton pregnancy. This study used data from the 2017 Indonesia Demographic and Health Survey (IDHS). Multinomial logistic regression was performed to examine the relationship between AMA and elective c-section. The final sample analysis comprises 4,988 observations. This study found that AMA at birth significantly associated with elective c-section among primiparous women with singleton pregnancy (RRR: 7.98; 95\% CI 4.85-13.11). The possible explanation of this finding is pre-pregnancy morbidities, abnormal labor, and uterine dysfunction among the AMA group. Despite the comprehensive dataset, the study has limitations. The design does not allow for a causal interpretation of the associations studied. Further research through cohort studies including biological variables and maternal preferences are recommended.
\end{abstract}

Keyword: advanced maternal age, elective c-section, Indonesia

\section{Introduction}

The cesarean section is a surgical procedure to save a life when complications appear during pregnancy and delivery and became a reasonable alternative for vaginal delivery [1]. The global cesarean section rate is rising, including in Indonesia. Indonesia's cesarean section rate was $4.3 \%$ in 1997 and became $17 \%$ in 2017 [2]. ${ }^{2}$ The cesarean section is the most common surgical procedure performed among women [3]. The increasing cesarean section is partly because of the rising number of women requesting an elective cesarean section [4]. World Health Organization (WHO) suggested cesarean section limit rates at $15 \%$ in 1985 , and it lowered to $10 \%$ in 2014 . The proportion of cesarean section rate over the recommended threshold is not associated with maternal and newborn mortality [5].

Although cesarean section has some benefits for both mothers and children, this procedure is associated with immediate and late maternal and perinatal risks [6]. Direct adverse effects of the cesarean section include postpartum hemorrhage and the reduction of the immunity of infants. The cesarean section's late adverse effects also increase the risk of asthma, allergies, diabetes mellitus, cancer, and hematopoietic development problems [7], [8]. ${ }^{7}$ Women with cesarean section were more likely to receive blood transfusions, hysterectomy, and experience increased maternal mortality risk than women who gave vaginal birth[9]. From an economic perspective, cesarean section also significantly more expensive than vaginal delivery [10]. 
The existing literature suggests that the increase of cesarean section is predominantly due to advanced maternal age, particularly in nulliparous women. Advanced maternal age is defined as childbearing in a woman over 35 years of age, and it is increasing globally [11]. [12]. Based on the 2017 IDHS, the median age at first birth for women aged 25-49 is 22.4 years. Social demographic and economic status also influence the age at first birth. The median age at first birth increases with education and wealth [13]. Women who are postponing their pregnancies until late in their productive life increased in most of the industrialized world, social, educational, and demographic changes [14].

Four indirect factors may influence maternal mortality and morbidity. Women face significantly heightened risks of pregnancy-related morbidity and mortality when they are "too young, too old, too frequent, or too many." Advanced maternal age will be increased the complications of pregnancy. Childbirth and infant outcomes were worse than the younger maternal age. Pregnancy in advanced maternal age is associated with increased risk of abortion, chromosomal abnormalities, maternal death, and complication. Also, perinatal morbidity and mortality, intrauterine fetal death (IUFD), and premature labor have increased significantly in women with advanced maternal age [15]. Advanced maternal age at birth is often cited as a reason for the rise in the cesarean section. However, it is not clear that the increasing cesarean section is caused by medical complications increasing with maternal age or maternal age per se. Health professionals' assumption of maternal age as a risk factor may lower the cesarean section threshold in advanced maternal age [14]. Primiparous women tend to have prolonged labor and delivery. Also, primiparous women were admitted earlier and more exposed to hospital intervention during labor and birth than multiparous women. We examined the association between advanced maternal age and elective cesarean section in primiparous women with singleton pregnancy.

\section{Method}

This study used data from the 2017 Indonesia Demographic and Health Survey (IDHS). The IDHS is a nationally representative cross-sectional survey that collects various demographic and health indicators on the individual and household-level. It is part of the worldwide Demographic and Health Survey (DHS) program and was conducted by the National Population and Family Planning Board (BKKBN) in collaboration with Statistics Indonesia (BPS) and the Ministry of Health (MoH) of Indonesia. The sampling frame for the 2017 IDHS used the updated list of households in the selected census blocks (CBs) taken from Indonesia's 2010 Population Census. A CB was a geographic area that contains 80-120 households selected through systematic sampling. Respondents were selected using two-stage stratified sampling. In the first stage, $\mathrm{CBs}$ were selected using probability proportional to size (PPS) from those CBs based on wealth index categories. Next, 25 households in each CB were randomly selected as respondents. More detailed information on the sampling methods has been described elsewhere [16].

This study's samples were primiparous women aged 15 - 49 years old who gave the singleton live birth five years before the survey. These samples were interviewed about the modes of delivery in their most recent birth. Respondents who answered did not know, or missing were excluded from the analysis, which is equivalent to 4,988 women. The dependent variable in this study is the mode of delivery. The delivery mode was divided into three categories, ' 0 ' if the delivery mode is vaginal delivery. Vaginal deliveries include normal deliveries, induction deliveries, and assisted deliveries with vacuum and forceps extraction. Value ' 1 ' if the mode of delivery is the emergency cesarean section, and ' 2 ' if the mode of 
delivery is the elective cesarean section. The main exposure variable was maternal age categorized into two groups: ages lower than 35 years old and 35 years or older. The age group of lower than 35 years was used as the reference group, as it had the lowest risk profile.

We included several other variables as confounders: socio-demographic factors (residence, education level, working status, and economic status), obstetrics factors (pregnancy complication, antenatal care, birth weight, and children's sex), and health insurance ownership. We used descriptive statistics to summarize the characteristics of the study population. We summarized the categorical variables using frequencies with their associated percentages. We examined the relationship between explanatory variables and the outcome of interest using logistic regression. We employed multinomial logistic regression to estimate confounderadjusted relative risk ratios (RRRs) with $95 \%$ confidence intervals (CIs). We put the variables on multivariate regression based on theoretical consideration. All statistical analyses were performed using Stata 15.1.

\section{Result}

The final sample analysis comprises 4,988 observations. This study found that almost one in five children $(19.2 \%)$ was delivered by cesarean section. Of which, $15.1 \%$ was emergency cesarean section, and $4.1 \%$ was elective cesarean section. According to the maternal age group, this study found that the proportion of cesarian section increased with increasing of maternal age. More than one-fifth $(21.8 \%)$ of women in advanced maternal age group have elective cesarean section.

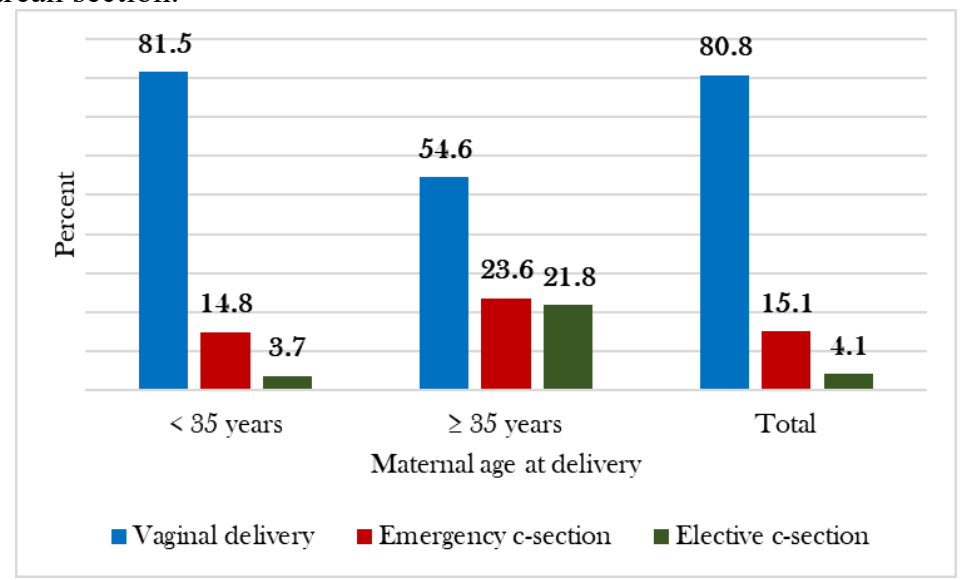

Fig. 1. Mode of delivery among final the sample analysis, Stratified by maternal age at delivery

Table 1 showed characteristics of the sample according to the mode of delivery. According to socio-demographic status, the proportion of elective cesarean section was higher in women who lived in urban (5.6\%) than rural $(2.7 \%)$, high education $(9.2 \%)$, and from the richest economics status $(8.3 \%)$. Women with pregnancy complications also had higher cesarean section proportion than women with healthy pregnancies. 
Table 1. Background Characteristics of Women according to Mode of Delivery

\begin{tabular}{|c|c|c|c|}
\hline \multirow[t]{2}{*}{ Variable } & Vaginal Birth & $\begin{array}{c}\text { Emergency c- } \\
\text { section }\end{array}$ & $\begin{array}{c}\text { Elective c- } \\
\text { section }\end{array}$ \\
\hline & $\mathrm{n}(\%)$ & $\mathrm{n}(\%)$ & $\mathrm{n}(\%)$ \\
\hline \multicolumn{4}{|l|}{ Residence } \\
\hline Urban & $1,825(75.4)$ & $459(19.0)$ & $137(5.6)$ \\
\hline Rural & $2,205(85.9)$ & $293(11.4)$ & $69(2.7)$ \\
\hline \multicolumn{4}{|l|}{ Maternal education } \\
\hline Low & $728(90.6)$ & $59(7.3)$ & $17(2.1)$ \\
\hline Middle & 2,694 (81.9) & $488(14.8)$ & $107(3.3)$ \\
\hline High & $608(67.9)$ & 205 (22.9) & $82(9.2)$ \\
\hline \multicolumn{4}{|l|}{ Working status } \\
\hline Did not work & $2,352(83.1)$ & 394 (13.9) & $86(3.0)$ \\
\hline Work & $1,678(77.8)$ & $358(16.6)$ & $120(5.6)$ \\
\hline \multicolumn{4}{|l|}{ Economic status } \\
\hline Poorest & $809(91.2)$ & $64(7.2)$ & $14(1.6)$ \\
\hline Poorer & $890(86.7)$ & $114(11.1)$ & $22(2.2)$ \\
\hline Middle & $939(83.8)$ & $149(13.3)$ & $33(2.9)$ \\
\hline Richer & $770(73.7)$ & $214(20.4)$ & $62(5.9)$ \\
\hline Richest & $622(68.4)$ & $211(23.3)$ & $75(8.3)$ \\
\hline \multicolumn{4}{|c|}{ Pregnancy complication } \\
\hline None & $3,408(83.3)$ & $538(13.2)$ & $144(3.5)$ \\
\hline Any & $622(69.3)$ & $214(23.9)$ & $62(6.9)$ \\
\hline \multicolumn{4}{|l|}{ Antenatal care } \\
\hline No K4 & $814(87.3)$ & $96(10.3)$ & $23(2.4)$ \\
\hline K4 & $3,216(79.3)$ & $656(16.2)$ & $183(4.5)$ \\
\hline \multicolumn{4}{|l|}{ Health Insurance } \\
\hline No & $1,823(85.0)$ & $271(12.6)$ & $51(2.4)$ \\
\hline Yes & $2,207(77.6)$ & 481 (16.9) & $155(5.5)$ \\
\hline \multicolumn{4}{|l|}{ Birth weight } \\
\hline Normal & $3,747(81.0)$ & $689(14.9)$ & $192(4.1)$ \\
\hline Low & $283(78.6)$ & $63(17.5)$ & $14(3.9)$ \\
\hline \multicolumn{4}{|l|}{ Sex of child } \\
\hline Male & $2,037(79.0)$ & 427 (16.6) & $114(4.4)$ \\
\hline Female & $1,993(82.7)$ & $325(13.5)$ & $92(3.8)$ \\
\hline TOTAL & $4030(80.8)$ & $752(15.1)$ & $206(4.1)$ \\
\hline
\end{tabular}

Table 2 showed the association between maternal age at birth and elective cesarean section after adjusting for some potential confounders. This study found that advanced maternal age at birth was significantly associated with emergency and elective cesarean sections among 
primiparous women with singleton pregnancy. Women with advanced maternal age at birth were seven times more likely to have elective cesarean section than younger ones. Furthermore, this study also found that the risk of emergency cesarean section increased in advanced maternal age at birth.

Table 2. Results of the multivariable logistic regression analysis

\begin{tabular}{|c|c|c|c|c|}
\hline \multirow{2}{*}{ Variable } & \multicolumn{2}{|c|}{ Emergency c-section } & \multicolumn{2}{|c|}{ Elective c-section } \\
\hline & RRR & $95 \% \mathrm{CI}$ & RRR & $95 \% \mathrm{CI}$ \\
\hline \multicolumn{5}{|l|}{ Maternal age at birth } \\
\hline$\leq 35$ years old & Reference & & Reference & \\
\hline$>35$ years old & $2.31 * * *$ & $(1.47-3.61)$ & $7.98 * * *$ & $(4.85-13.11)$ \\
\hline \multicolumn{5}{|l|}{ Residence } \\
\hline Urban & $1.27 * *$ & $(1.06-1.52)$ & 1.28 & $(0.91-1.80)$ \\
\hline Rural & Reference & & Reference & \\
\hline \multicolumn{5}{|l|}{ Maternal education } \\
\hline Low & Reference & & Reference & \\
\hline Middle & $1.75^{* * *}$ & $(1.31-2.35)$ & 1.28 & $(0.75-2.19)$ \\
\hline High & $2.39 * * *$ & $(1.69-3.37)$ & $2.48 * *$ & $(1.37-4.51)$ \\
\hline \multicolumn{5}{|l|}{ Working status } \\
\hline Did not work & Reference & & Reference & \\
\hline Work & 0.98 & $(0.83-1.16)$ & 1.19 & $(0.87-1.63)$ \\
\hline \multicolumn{5}{|l|}{ Economic status } \\
\hline Poorest & Reference & & Reference & \\
\hline Poorer & $1.4^{*}$ & $(1.01-1.94)$ & 1.33 & $(0.67-2.62)$ \\
\hline Middle & $1.54 * *$ & $(1.12-2.13)$ & 1.53 & $(0.80-2.94)$ \\
\hline Richer & $2.33 * * *$ & $(1.68-3.21)$ & $2.79 * *$ & $(1.48-5.28)$ \\
\hline Richest & $2.33 * * *$ & $(1.65-3.30)$ & $2.77 * *$ & $(1.42-5.41)$ \\
\hline \multicolumn{5}{|c|}{ Pregnancy complication } \\
\hline None & Reference & & Reference & \\
\hline Any & $1.91 * * *$ & $(1.59-2.30)$ & $1.93 * * *$ & $(1.39-2.66)$ \\
\hline \multicolumn{5}{|l|}{ Antenatal care } \\
\hline No K4 & Reference & & Reference & \\
\hline K4 & $1.34 *$ & $(1.05-1.69)$ & 1.28 & $(0.81-2.03)$ \\
\hline \multicolumn{5}{|l|}{ Health Insurance } \\
\hline No & Reference & & Reference & \\
\hline Yes & $1.19^{*}$ & $(1.00-1.41)$ & $1.83 * * *$ & $(1.30-2.56)$ \\
\hline \multicolumn{5}{|l|}{ Birth weight } \\
\hline Normal & Reference & & Reference & \\
\hline Low & 1.18 & $(0.88-1.59)$ & 0.9 & $(0.51-1.59)$ \\
\hline
\end{tabular}




\begin{tabular}{|c|c|c|c|c|}
\hline \multicolumn{5}{|c|}{ Sex of child } \\
\hline Male & $1.26 * *$ & $(1.07-1.48)$ & 1.16 & $(0.87-1.55)$ \\
\hline Female & Refere & & Reference & \\
\hline
\end{tabular}

${ }^{*}$ p-value $<0.05,{ }^{* *}$-value $<0.01,{ }^{* * *}$ p-value $<0.001$

\section{Discussion}

Our analysis confirms the findings of other studies that advanced maternal age at childbirth is positively associated with the likelihood of both emergency and elective cesarean section. Our result is consistent with several previous studies reporting a significant association between advanced maternal age and cesarean section. Comprehensive adjustment for known confounders was conducted. Using this approach, we include some potential confounders in the final model. Timofeev et al. found that the cesarean section's risk increased in nulliparous women aged 40-45 years compared to women ages 25-29 years [17]. Moreover, Richard et al. found regardless of parity, cesarean section risk was increased with increasing maternal age [18].

A possible explanation of this finding is pre-pregnancy morbidities. The risk of many diseases increases with increased maternal age. Increased rates of chronic diseases among women at advanced maternal age may have contributed to higher cesarean birth rates in this group [15]. Uterine dysfunction is also mentioned as the cause of our result. Another possible explanation is that abnormal labor patterns reduced the efficiency of myometrial. The myometrium incompetency decreased the number of oxytocin receptors, which were argued as possible physiological factors for the increasing cesarean rate in advanced maternal age group [19]. Furthermore, dystocia and abnormal placental implantation increased in advanced maternal age were argued to increase cesarean section in this group [14].

In addition, maternal age alone may affect a physician's decision about the mode of delivery. "High-risk labeling" and maternal anxiety may influence the preferences of both women and obstetricians concerning the mode of delivery. It has been suggested that the surprisingly high risk of elective cesarean delivery among advanced maternal age is partly attributable to differences in care and maternal preference. However, previous studies showed that maternal request is not a prominent factor in increasing cesarean rates among women of all ages. Nevertheless, the fact might be different for women at advanced maternal age identified by their health care practitioners as high-risk pregnant women [20-22].

\section{Conclusion}

This study revealed that advanced maternal age was significantly associated with the elective cesarean section. This study contributed to the hypothesis of a strong association between increased maternal age and elective cesarean section. The association could not be explained by maternal comorbidities, biological factors such as uterine dysfunction, or artificial reproductive technologies due to infertility. This study also cannot explain the maternal reference. Due to these results, health workers should inform related risks to advanced maternal age women, including delivery by cesarean section. Close monitoring of women in this group must also be done to ensure both mother and baby's health, such as properly antenatal checkups. 


\section{Ethical approval}

The Institutional Review Board of Inner City Fund ( ICF ) International and ORC Macro (ICF IRB FWA0 000 0845) granted ethical approval for the 2017 IDHS. It adhered to the U.S. Department of Health and Human Services requirement to protect human subjects; the participants' information was kept anonymous.

\section{Conflict of Interest}

The authors declare no conflict of interest.

\section{References}

[1] Greene MF, Creasy RK, Resnik R, Iams JD, Lockwood CJ, Moore T. Creasy and Resnik's Maternal-Fetal Medicine: Principles and Practice E-Book. Elsevier Health Sciences; 2008.

[2] Statistics Indonesia, National Population and Family Planning Board, Ministry of Health II. Indonesia Demographic and Health Survey 2017. National Population and Family Planning Board (BKKBN); 2018.

[3] Pfuntner A, Wier LM, Stocks C. Most frequent procedures performed in US hospitals, 2010: Statistical Brief\# 149. 2006;

[4] Størksen HT, Garthus-Niegel S, Adams SS, Vangen S, Eberhard-Gran M. Fear of childbirth and elective caesarean section: a population-based study. BMC Pregnancy Childbirth. 2015;15(1):221.

[5] World Health Organization Human Reproduction Programme 10 April 2015. WHO Statement on caesarean section rates. Reprod Health Matters. 2015;23(45):149-50.

[6] Souza JP, Gülmezoglu A, Lumbiganon P, Laopaiboon M, Carroli G, Fawole B, et al. Caesarean section without medical indications is associated with an increased risk of adverse short-term maternal outcomes: the 2004-2008 WHO Global Survey on Maternal and Perinatal Health. BMC Med. 2010;8(71):1-10.

[7] Beogo I, Mendez Rojas B, Gagnon M-P. Determinants and materno-fetal outcomes related to cesarean section delivery in private and public hospitals in low- and middleincome countries: a systematic review and meta-analysis protocol. Syst Rev. 2017;6(1):5.

[8] Grivell R, Dodd JM. Short- and long-term outcomes after cesarean section. 2011;20515.

[9] Villar J, Carroli G, Zavaleta N, Donner A, Wojdyla D, Faundes A, et al. Maternal and neonatal individual risks and benefits associated with caesarean delivery: multicentre prospective study. BMJ Br Med J. 2007;335(7628):1025.

[10] Anggraini AB, Andayasari L. Sources of funding for caesarean section in two hospitals in Jakarta. Heal Sci J Indones. 2013;4(2):93-7.

[11] Moore EK, Irvine LM. The impact of maternal age over forty years on the caesarean section rate: six year experience at a busy district general hospital. J Obstet Gynaecol (Lahore). 2014;34(3):238-40.

[12] Tromp M, Ravelli ACJ, Reitsma JB, Bonsel GJ, Mol BW. Increasing maternal age at first pregnancy planning: health outcomes and associated costs. J Epidemiol Community Heal. 2011;65(12):1083-90.

[13] Sjafii A, Purnami SW, Wibisono SP, Mayliawati A, Aida FN. Analisis Data Sdki 2017: Determinan Umur Pertama Wanita Melahirkan Di Jawa Timur Dengan Pendekatan Analisis Survival. In: PERTEMUAN ILMIAH NASIONAL WIDYAISWARA 
BKKBN. 2019. p. 6

[14] Rydahl E, Declercq E, Juhl M, Maimburg RD. Cesarean section on a rise-Does advanced maternal age explain the increase? A population register-based study. PLoS One. 2019;14(1).

[15] Lean SC, Derricott H, Jones RL, Heazell AEP. Advanced maternal age and adverse pregnancy outcomes: a systematic review and meta-analysis. PLoS One. 2017;12(10).

[16] BKKBN, BPS, Kementerian Kesehatan RI. Survei demografi dan kesehatan Indonesia 2017: Kesehatan reproduksi remaja. The 2017 Indonesia Demographic and Health Survey. 2018.

[17] Timofeev J, Reddy UM, Huang C-C, Driggers RW, Landy HJ, Laughon SK. Obstetric complications, neonatal morbidity, and indications for cesarean delivery by maternal age. Obstet Gynecol. 2013;122(6):1184.

[18] Richards MK, Flanagan MR, Littman AJ, Burke AK, Callegari LS. Primary cesarean section and adverse delivery outcomes among women of very advanced maternal age. J Perinatol. 2016;36(4):272-7.

[19] Walker KF, Thornton JG. Advanced maternal age. Obstet Gynaecol Reprod Med. 2016;26(12):354-7.

[20] Bayrampour H, Heaman M. Advanced maternal age and the risk of cesarean birth: a systematic review. Birth. 2010;37(3):219-26.

[21] McCourt C, Weaver J, Statham H, Beake S, Gamble J, Creedy DK. Elective cesarean section and decision making: a critical review of the literature. Birth. 2007;34(1):65-79.

[22] Declercq ER, Sakala C, Corry MP, Applebaum S. Listening to mothers II: Report of the second national US survey of women's childbearing experiences. J Perinat Educ. 2007;16(4):9-14. 